\title{
Cultivo de células-tronco derivadas de tecido adiposo: uma análise crítica
}

\author{
Culture of adipose-derived stem cells: \\ a critical analysis
}

\author{
Pedro Ribeiro Soares de Ladeira', Cesar Isaac ${ }^{2}$, Yeda Midori Nakamura ${ }^{3}$, Rafael \\ Mamoru Carneiro Tutihashi ${ }^{4}$, André Oliveira Paggiaro ${ }^{5}$, Marcus Castro Ferreira ${ }^{6}$
}

\begin{abstract}
Ladeira PRS, Isaac C, Nakamura YM, Tutihashi RMC, Paggiaro AO, Ferreira MC. Cultivo de células-tronco derivadas de tecido adiposo: uma análise crítica / Culture of adipose-derived stem cells: a critical analysis. Rev Med (São Paulo). 2012;91(4):246-52.
\end{abstract}

RESUMO: Introdução: células-tronco derivadas de tecido adiposo (ADSCs) são pluripotentes, tem coleta pouco invasiva e apresentam alto rendimento celular em cultura, além do fato de o número de lipoaspirações, a principal fonte destas células, estar aumentando ao redor do mundo. A Cirurgia Plástica tem encontrado benefícios de seu uso em diversas áreas, o que ressalta a importância de se analisar criticamente os protocolos de cultivo atualmente utilizados. Objetivo: descrever detalhadamente o protocolo de cultivo adotado pelo nosso laboratório para podermos realizar uma análise crítica sobre o cultivo de ADSCs. Método: excedentes de tecido adiposo foram doados ao laboratório com finalidade de pesquisa por cinco pacientes de ambos os sexos e faixa etária de 20 a 45 anos. De cada paciente, $30 \mathrm{~mL}$ do material gorduroso foram coletados em frasco estéril e transportados ao laboratório de cultura celular, onde foram submetidos, por $45 \mathrm{~min}$, à digestão enzimática por $30 \mathrm{mg}$ de colagenase tipo IA diluída em $30 \mathrm{~mL}$ de meio de Dulbecco Modificado por Eagle (DMEM) e posteriormente centrifugados para que se isolem as células da matriz extracelular. A amplificação das culturas foi feita com solução de tripsina 0,05\% + EDTA 0,02\%. Para congelamento, utilizou-se meio de congelamento composto por 60\% DMEM, 10\% dimetilsulfóxido (DMSO) e $30 \%$ SBF. Resultados: o protocolo apresentado para o cultivo de ADSCs demonstrou um cultivo celular satisfatório, completando três passagens de cultura em todas as amostras, com posterior congelamento e descongelamento. Conclusões: a literatura científica nos indica que a colagenase possibilita extração e isolamento de ADSCs, devendo-se atentar ao tipo utilizado. Quanto ao congelamento, dado a citotoxicidade do DMSO, novos protocolos com grandes amostras substituindo este crioprotetor por trealose devem ser testados, visto que este último produziu bons resultados e não apresentou efeitos tóxicos nos estudos já publicados.

DESCRITORES: Células-tronco; Células-tronco mesenquimais; Células-tronco adultas; Tecido adiposo; Técnicas de cultura de células; Meios de cultivo condicionados; Colagenases.

Trabalho realizado no Laboratório de Pesquisas em Cultura Celular e Feridas - LIM04 - Divisão de Cirurgia Plástica - HCFMUSP.

Este estudo faz parte do projeto FAPESP (Processo Número 12/00343-2) intitulado: "Interferência de células-tronco derivadas de tecido adiposo (ADSC) na atividade de produtos de glicação avançada (AGE) em fibroblastos cultivados oriundos de feridas de indivíduos diabéticos" / "Interference of ADSCs in the activity of advanced glycation end products (AGE) on cultured fibroblasts from diabetic wounds".

1. Acadêmico do curso de Medicina da Faculdade de Medicina da Universidade de São Paulo - FMUSP.

2. Médico responsável pelo Laboratório de Pesquisas em Cultura Celular e Feridas - LIM 04 HCFMUSP.

3. Bióloga membro do Laboratório de Pesquisas em Cultura Celular e Feridas - LIM 04 - HCFMUSP.

4. Médico membro do Laboratório de Pesquisas em Cultura Celular e Feridas - LIM 04 - HCFMUSP.

5. Médico responsável pelo Banco de Tecidos do Instituto Central do Hospital das Clínicas da FMUSP.

6. Professor Titular da Disciplina de Cirurgia Plástica - FMUSP e Diretor Técnico da Divisão de Cirurgia Plástica e Queimados HCFMUSP.

Endereço para correspondência: Cesar Isaac. LIM 04 - Av. Dr. Arnaldo, 455, Sala 1363 - Cerqueira César, São Paulo, SP, CEP:01296-903. e-mail: cesaris@uol.com.br 
SUMMARY: Introduction: adipose-derived stem cells (ADSCs) are pluripotent and present little invasive collection and high cell yield in culture, besides the fact that the number of liposuctions, the main source of these cells, is increasing around the world. Plastic Surgery has found the benefits of the use of those cells in several areas, which increases the importance of critically analyzing the protocols currently used for cell cultivation. Objective: to describe in detail the cultivation protocol adopted by our laboratory in order to perform a critical analysis of the culture of ADSCs. Method: surpluses of adipose tissue were donated to the laboratory with research purposes for 5 patients of both genders and age between 20 and 45 years. From each patient, $30 \mathrm{~mL}$ of fatty material was collected in a sterile flask and transported to the laboratory for cell culture, where they were subjected during $45 \mathrm{~min}$ to enzymatic digestion by $30 \mathrm{mg}$ of type IA collagenase diluted in $30 \mathrm{~mL}$ of Dulbecco's Modified Eagle Medium (DMEM) and then centrifuged to isolate the cells from the extracellular matrix.

\section{INTRODUÇÃO}

Dentro do enfoque de medicina regenerativa o uso de células-tronco se mostra interessante, pois existem descrições de sua capacidade de interferência no processo de cicatrização ${ }^{1}$, dado que são autorenováveis, viáveis a longo prazo e multipotenciais quanto à diferenciação². Elas podem ser classificadas em dois tipos: embrionárias e adultas.

Dentre as células-tronco adultas estão as ADSCs ("adipose derived stem cells" ou célulastronco derivadas de tecido adiposo), as quais são obtidas a partir do estroma de sustentação do tecido adiposo branco e podem se diferenciar em: osteoblastos, miócitos cardíacos, condrócitos, células neurais, células de músculo liso, hepatócitos, epitélio e em endotélio ${ }^{3}$. As ADSC apresentam morfologia muito semelhante a fibroblastos, com aspecto alongado e citoplasma fusiforme ${ }^{4}$. No tecido adiposo, as ADSC são encontradas à razão de 1:100 a 1:1500 adipócitos ${ }^{5}$. Esse valor é considerado muito superior àquele descrito para as células provenientes da medula ósseo ${ }^{6}$. Quando comparadas, histologicamente, a adipócitos, as ADSC não possuem gotículas gordurosas tão características das células do tecido gorduroso. A análise molecular in vitro revela que a expressão nuclear de proteínas de membrana assim como de citocinas modifica-se nas ADSC, aproximando seu fenótipo àquele encontrado em células-tronco provenientes de tecido músculo-esquelético, mas também de medula óssea ${ }^{7}$. Uma vez cultivadas, as ADSC apresentam-se em camada única de células, que têm caracteristicamente aspecto achatado e cerca de 25 a 30 micrômetros de diâmetro. Quando a cultura
The amplification of the cultures was made with $0.05 \%$ trypsin solution + EDTA $0.02 \%$. For cryopreservation was used freezing media consisting of $60 \%$ DMEM, $10 \%$ dimethylsulfoxide (DMSO) and 30\% FBS. Results: The above protocol for growing ADSCs obtained a satisfactory cell culture, completing three cell passages in all samples, with subsequent freezing and thawing. Conclusions: The scientific literature indicates that collagenase get the best results in the extraction and isolation of ADSCs, paying attention to the type used. Regarding freezing, given the cytotoxicity of DMSO, new protocols with large samples replacing this cryoprotectant by trehalose should be tested, since the latter has produced good results and showed no toxic effects in published studies.

KEYWORDS: Stem cell; Mesenchymal stem cells; Adult stem cells; Adipose tissue; Cell culture techniques; Culture media, conditioned; Collagenases.

aproxima-se da confluência, as células assumem formato de fuso, tornando-as ainda mais semelhantes a fibroblastos ${ }^{4}$. Nos recipientes em que se iniciam as culturas existe uma grande variedade de células (células hematopoiéticas, pericitos, células endoteliais, e até mesmo algumas células de músculo liso). À medida que as culturas são amplificadas, o número dessas outras células decai rapidamente, uma vez que o meio de cultura utilizado para nutrir as células é específico para crescimento de ADSC ${ }^{4}$.

As utilizações clínicas e laboratoriais de ADSCs mostram aspectos vantajosos, pois as células derivadas de tecido adiposo necessitam tem coleta pouco invasiva e apresentam alto rendimento celular em cultura ${ }^{8}$, além do fato de o número de lipoaspirações, a principal fonte destas células, estar aumentando concomitante ao número total de obesos no mundo'.

Atualmente, a literatura científica tem se focado nos potenciais benefícios das ADSCs, especialmente quanto ao processo de cicatrização $0^{1,10}$. Concomitantemente, muitos grupos de pesquisa procuram modos de melhorar o tratamento de úlceras crônicas de indivíduos diabéticos, na qual os produtos de glicação avançada (advanced glycation end products ou AGEs) tem sido apontados como principais responsáveis pela cronicidade da ferida.

Muitas substâncias anti-AGEs vem sendo pesquisadas para agir nas úlceras crônicas de diabéticos, incluindo a lisozima, cujo mecanismo de neutralização de glicotoxinas foi sugerido por Zheng et al. ${ }^{1{ }^{1}}$. Adicionalmente, descobriu-se que as BMSSCs (células-tronco derivadas de estroma de medula óssea ou "bone marrow stromal stem cells"), 
cujo comportamento se assemelha ao das ADSCs ${ }^{12}$, tem a lisozima como um de seus principais produtos extracelulares ${ }^{13}$.

No presente estudo descrevemos detalhadamente e ilustramos o protocolo de cultivo adotado pelo nosso laboratório para podermos realizar uma análise crítica sobre o cultivo de ADSCs.

\section{MÉTODOS}

\section{Aspectos éticos}

O estudo obteve aprovação da Comissão de Ética para Análise de Projetos de Pesquisa - CAPPesq da diretoria clínica do Hospital das Clínicas e da Faculdade de Medicina da Universidade de São Paulo (número do projeto: 0877/11).

Os pacientes foram informados sobre o propósito e conseqüências do estudo, e posteriormente foi solicitada autorização de participação no estudo mediante preenchimento do termo de consentimento livre e esclarecido.

Os experimentos foram desenvolvidos no LIM 04 - Laboratório de Pesquisas em Cultura Celular e Feridas da Disciplina de Cirurgia Plástica do HCFMUSP.

\section{Obtenção e cultura de ADSCs}

Excedentes de tecido adiposo foram doados ao laboratório com finalidade de pesquisa por cinco pacientes de ambos os sexos e dentro da faixa etária de 20 a 45 anos.

Para cada paciente, $30 \mathrm{~mL}$ do material gorduroso foram coletados em frasco estéril e transportados ao laboratório de cultura celular, onde foram submetidos por $45 \mathrm{~min}$ à digestão enzimática por $30 \mathrm{mg}$ de colagenase tipo IA diluída em $30 \mathrm{~mL}$ de meio de Dulbecco Modificado por Eagle (DMEM) e posteriormente centrifugados para que se isolem as células da matriz extracelular. Sendo estas menos densas, elas decantaram no fundo do frasco formando um precipitado celular. O precipitado celular foi ressuspendido em $12 \mathrm{~mL}$ de DMEM acrescido de $10 \%$ de SBF com estreptomicina $100 \mu \mathrm{g} / \mathrm{mL}$ / penicilina $100 \mathrm{UI} / \mathrm{mL}$ / anfotericina $B$ 0,25 $\mu \mathrm{g} / \mathrm{mL}$ (por nós denominado D10) e transferido para garrafas de cultura de células de $75 \mathrm{~cm}^{2}$ de área, as quais foram incubadas a $37^{\circ} \mathrm{C} \mathrm{em}$ atmosfera de $5 \%$ de $\mathrm{CO}_{2}$.

\section{Amplificação}

A adição de $12 \mathrm{~mL}$ de solução de tripsina $0,05 \%$ + EDTA $0,02 \%$ nas garrafas de cultura permitiu a liberação das células. Após 1 a 2 min em estufa a $37^{\circ} \mathrm{C}$ em uma atmosfera de $5 \%$ de $\mathrm{CO}_{2}$, essa reação enzimática foi interrompida pela adição de $5 \mathrm{~mL}$ de DMEM $+10 \%$ de soro bovino fetal (SBF) inativado a $56^{\circ} \mathrm{C} / 30 \mathrm{~min}$. O conteúdo aspirado foi transferido para um tubo de fundo cônico e centrifugado por $5 \mathrm{~min}$ a $350 \mathrm{~g}$. O sobrenadante foi descartado e as células precipitadas foram, então, ressuspendidas em D10 e transferidas para garrafas de cultura de células de $150 \mathrm{~cm}^{2}$ de área e incubado novamente à $37^{\circ} \mathrm{C}$ em atmosfera de $5 \%$ de $\mathrm{CO}_{2}$. A cada $72 \mathrm{~h}$, o meio de cultura foi trocado. Amplificações similares foram realizadas sempre que as células apresentaram semiconfluência, até atingir o número necessário de células para a realização dos experimentos propostos a seguir e/ou conservação das células por congelamento. A cada amplificação, o número de células foi contado em hemocitômetro de Neubauer.

\section{Congelamento}

As células dissociadas dos frascos de cultura, no momento da terceira amplificação das culturas (P3), foram ressuspendidas rapidamente em meio de congelamento, a saber: 60\% DMEM, $10 \%$ dimetilsulfóxido (DMSO) e $30 \%$ SBF.

Durante este processo, o meio de congelamento foi mantido no máximo a $4^{\circ} \mathrm{C}$ e as células nele ressuspendidas, foram transferidas para criotubos acondicionados em caixa de congelamento, contendo álcool isopropílico que, uma vez colocada à $-80^{\circ} \mathrm{C}$, possibilitará congelamento gradual e constante dessas suspensões celulares ( $1 \stackrel{\circ}{\circ}$ /minuto).

Após 24 horas, estes tubos foram transferidos para nitrogênio líquido, onde permaneceram estocados até o momento do uso.

\section{Descongelamento}

Iniciamos a etapa de descongelamento somente quando tínhamos células, obtidas de todas as amostras necessárias para o estudo, estocadas em nitrogênio líquido.

Os criotubos a serem descongelados foram colocados rapidamente em banho-maria a $37^{\circ} \mathrm{C}$, até que seu conteúdo começasse a liquefazer. Neste momento, o meio de cultura foi diluído em D10.

As células em suspensão foram transferidas para tubos de fundo cônico e submetidas à centrifugação a $800 \mathrm{~g}$ durante 5 minutos. Em cada tubo, o sobrenadante foi descartado e, o botão celular, ressuspendido em meio adequado para proliferação celular, quando então as células descongeladas foram novamente semeadas.

Todos os experimentos foram realizados até a quinta amplificação. 


\section{RESULTADOS}

\section{Extração e Isolamento de ADSCs}

A amplificação da culturas das cinco amostras de lipoaspirado foram coletadas e transportadas até o laboratório. Foi realizada a extração e o isolamento de ADSCs de acordo com o exposto pela Figura 1.

\section{Amplificação das Culturas de ADSCs}

A amplificação das culturas das cinco amostras foi realizada até a terceira passagem e de acordo com o exposto na Figura 2.

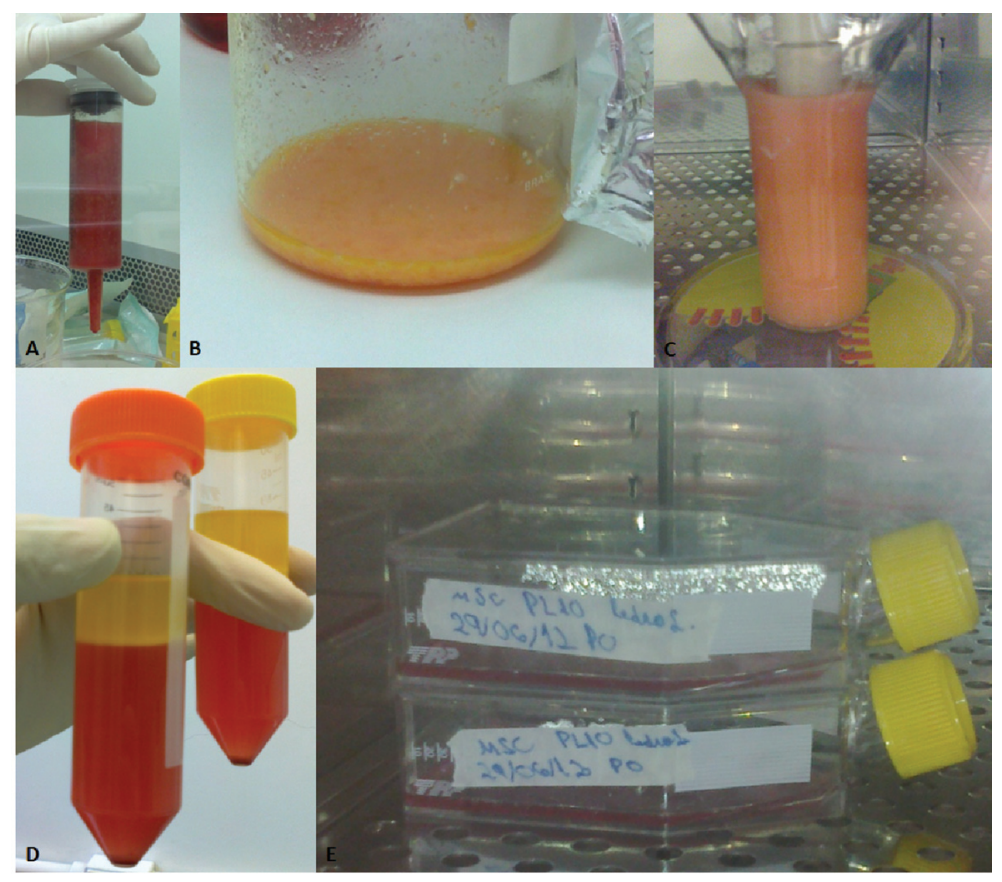

Figura 1. Extração e isolamento de ADSCs. A) lipoaspirado retirado da sala cirúrgica; B) lipoaspirado após lavagem seriada com soro fisiológico; $\mathrm{C}$ ) digestão enzimática do lipoaspirado lavado com colagenase tipo IA sob agitação magnética por 45 min.; D) precipitado celular e sobrenadante obtidos após centrifugação; E) cultura de ADSCs após ressuspensão do pellet em D10

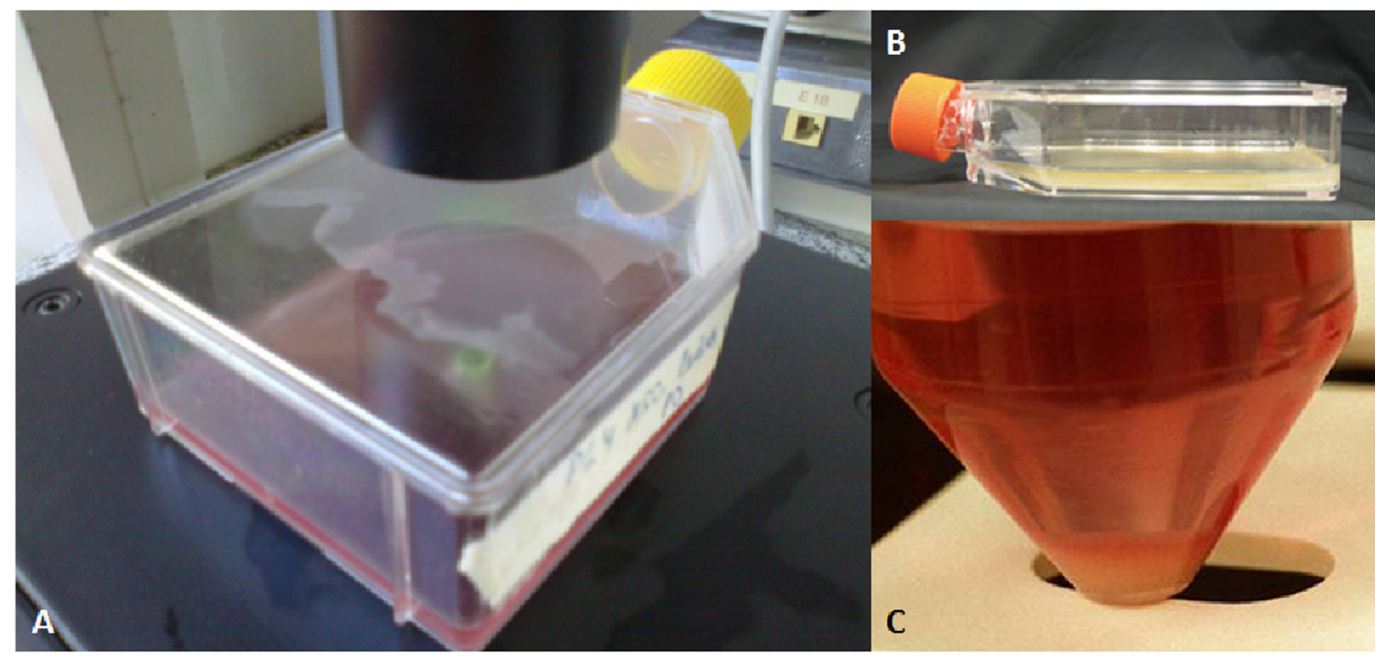

Figura 2. Amplificação da cultura de ADSCs. A) cultura de ADSCs em confluência; B) após remoção do meio e lavagem da garrafa com soro fisiológico, adicionou-se tripsina à cultura como apresentado na figura; C) adicionou-se D10 para interromper a ação da tripsina e depois centrifugou-se o líquido resultante, obtendo-se um precipitado celular como o da figura, o qual foi ressuspendido e transferido para uma área de cultura maior 


\section{Congelamento das ADSCs}

Assim que as culturas em terceira passagem atingiram confluência, realizou-se o congelamento das células de acordo com o exposto na Figura 3.

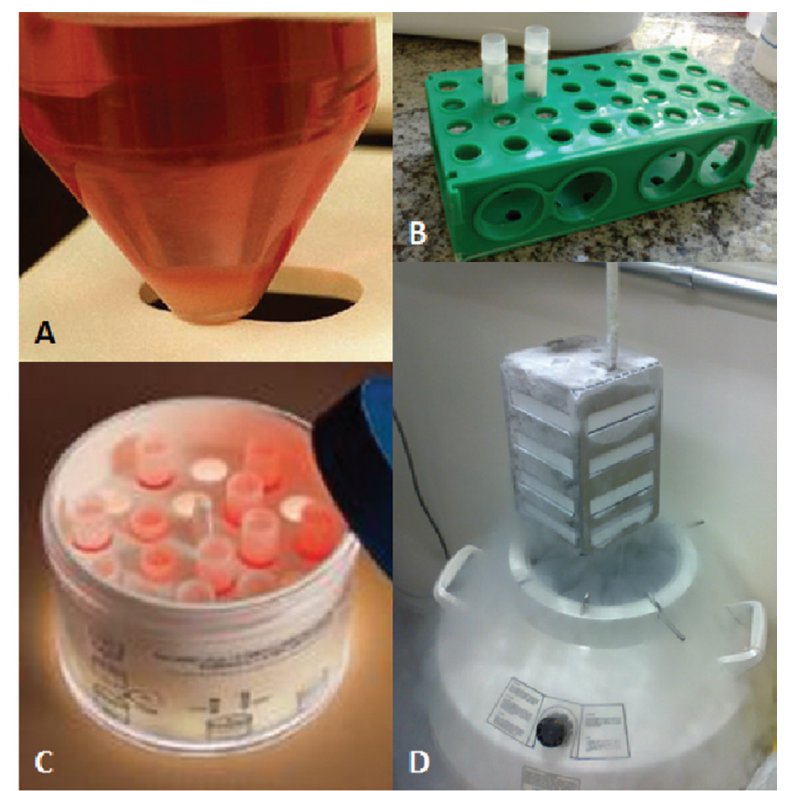

Figura 3. Congelamento de ADSCs. A) obteve-se um precipitado celular pelos mesmas etapas da amplificação; B) após contagem celular, ressuspendeu-se o precipitado em meio de congelamento e distribui-se o liquido em criotubos; C) transferência dos criotubos para um recipiente de congelamento com álcool isopropílico e armazenamento a $-80^{\circ} \mathrm{C}$; D) após 24 horas os criotubos foram colocados no nitrogênio líquido

\section{Descongelamento das ADSCs}

Logo que se atingiu a terceira passagem da cultura de ADSCs da quinta amostra de lipoaspirado, iniciou-se o descongelamento das células das outras amostras.

\section{DISCUSSÃO}

Os primeiros experimentos com cultivo celular datam do final do século dezenove ${ }^{14}$. Com o passar do tempo, este conhecimento foi sendo aprimorado e, em 1977, Dexter et al. descreveram as primeiras culturas de longa duração de células-tronco estromais derivadas da medula óssea, marcando o início do cultivo de células-tronco mesenquimais ${ }^{15,16}$. Com o grande crescimento do número de lipoaspirações realizadas ao redor do mundo, uma fonte menos invasiva e de maior rentabilidade celular passou a ser as células-tronco derivadas de tecido adiposo (ADSCs), cultivadas pioneiramente por Zuk et al. ${ }^{2}$.

Fadel et al. ${ }^{17}$ comparou quatro protocolos para obtenção e isolamento de ADSCs a partir de tecido adiposo perirrenal de ovelha, envolvendo lavagem com PBS e dissociação química com colagenase a $0,5 \%$, com o primeiro sendo incubado por 90 minutos à $37^{\circ} \mathrm{C}$ e $5 \%$ de $\mathrm{CO}_{2}$, o segundo por 45 minutos, o terceiro substituindo a colagenase por tripsina e o quarto sendo cultivado inicialmente com fragmentos de tecido adiposo. $\mathrm{O}$ uso de tripsina resultou em culturas inviáveis após 10 dias de cultivo, favorecendo a dissociação com colagenase que utilizamos. No entanto, o primeiro apresentou resultados melhores do que o segundo protocolo, o qual após 10 dias da extração apresentou células esféricas, mortas ou claramente diferenciadas. Assim, apesar de nosso método de extração se assemelhar ao segundo apresentado por Fadel (45 minutos de incubação durante a dissociação), nossos resultados foram mais semelhantes ao primeiro protocolo: aderência à garrafa de cultura após 24-48 horas e uma variedade de formatos neste período (triangular, dendrítica, redonda ou fusiforme). Uma das possíveis explicações para esta diferença entre os resultados pode estar no tipo de colagenase utilizada, que não foi informada pelo autor. Em nossos experimentos, à semelhança do estudo de Zuk et al. ${ }^{2}$, utilizamos a colagenase tipo IA, uma "colagenase bruta" ("crude collagenase"), a qual, por conter diversas outras enzimas além da colagenase, está entre as mais efetivas para digestões teciduais ${ }^{18}$. Deste modo, talvez não haja necessidade dos 90 minutos de dissociação química.

O congelamento de ADSCs, por sua vez, é uma técnica bastante debatida na literatura, principalmente com a difusão de seu uso clínico na cirurgia plástica $^{19}$. Em nosso estudo utilizamos um meio de congelamento composto por $60 \%$ de DMEM, $10 \%$ de dimetilsulfóxido (DMSO) e 30\% de SBF, esfriado a um grau por minuto até $-80^{\circ} \mathrm{C}$ em um recipiente com álcool isopropílico. A porcentagem de $10 \%$ de DMSO é a mais relevante na composição desse meio, dado que esse crioprotetor é citotóxico à temperatura ambiente. Por isso, apesar dessa porcentagem ser a padrão no congelamento de ADSCs, há uma tendência de diminuição e substituição parcial por trealose ${ }^{20,21}$, um agente crioprotetor sem toxicidade relevante ${ }^{22}$. Já, quanto à porcentagem de SBF, é comum encontrar trabalhos com porcentagens de até $90 \%$ e sem a presença de $\mathrm{DMEM}^{3,20}$, o que já se mostrou não ser um fator limitante ao processo, podendo-se realizar o congelamento até na ausência de SBF, utilizando somente DMEM e DMSO ${ }^{23}$.

Nosso método de extração, isolamento e cultura das ADSCs foi desenvolvido a partir do primeiro estudo a cultivar este tipo celular². Assim, podemos afirmar que houve uma reprodução bem sucedida dos experimentos e padronizamos o cultivo de ADSCs na 
rotina de nosso laboratório.

\section{CONCLUSÃO}

Nosso protocolo de cultivo apresentou resultados satisfatórios ao longo de todas as etapas abordadas. Adicionalmente, a literatura científica nos indica que a colagenase obtém os melhores

\section{REFERÊNCIAS}

1. Nakagami H, Maeda K, Morishita R, Iguchi S, Nishikawa $\mathrm{T}$, Takami Y, et al. Novel autologous cell therapy in ischemic limb disease through growth factor secretion by cultured adipose tissue-derived stromal cells. Arterioscler Thromb Vasc Biol. 2005;25:2542-7.

2. Zuk PA, Zhu M, Ashjian P, Ugarte DAD, Huang Jl, Mizuno H, Alfonso ZC, Fraser JK, Benhaim P, Hedrick $\mathrm{MH}$. Human adipose tissue is a source of multipotential stem cells. Mol Biol Cell. 2002;13:4279-95.

3. Bunnell BA, Flaat M, Gagliardi C, Patel B, Ripoll C. Adipose-derived stem cells: isolation, expansion and differentiation. Methods. 2008;45:115-20.

4. Miyazaki T, Kitagawa Y, Toriyama K, Kobori M, Torii $\mathrm{S}$. Isolation of two human fibroblastic cell populations with multiple but distinct potential of mesenchymal differentiation by ceiling culture of mature fat cells from subcutaneous adipose tissue. Differentiation. 2005;73:69-78.

5. Mizuno H, Hyakusoku H. Mesengenic potential and future clinical perspective of human processed lipoaspirate cells. J Nippon Med Sch. 2005;70(4):300-6.

6. Im GI, Shin YW, Lee KB. Do adipose tissue-derived mesenchymal stem cells have the same osteogenic and chondrogenic potential as bone marrow-derived cells? Osteoarthritis Cartilage. 2005;13: 845-53.

7. Rodriguez AM, Elabd C, Amri EZ, Ailhaud G, Dani C. The human adipose tissue is a source of multipotent stem cells. Biochimie. 2005;87:125-8.

8. Strem BM, Hicok KC, Zhu M, Wulur I, Alfonso Z, Schreiber RE, Fraser JK, Hedrick MH. Multipotential differentiation of adipose tissue-derived stem cells. Keio J Med. 2005;54:132-41.

9. Bunnel BA, Flaat M, Gagliardi C, Patel B, Ripoll C. Adipose-derived stem cells: Isolation, expansion and differentiation. Methods. 2008;45:115-20.

10. Kim WS, Byung-Soon P, Kim HK, Park BS, Kim HK, Park JS, et al. Evidence supporting antioxidant action of adipose-derived stem cells: Protection of human dermal fibroblasts from oxidative stress. J Dermatol Sci. 2008;49:133-42.

11. Zheng F, Cai W, Mitsuhashi T, Vlassara H. Lysozyme resultados na extração e isolamento de ADSCs, devendo-se atentar ao tipo utilizado. Quanto ao congelamento, dado a citotoxicidade do DMSO, novos protocolos com grandes amostras substituindo este crioprotetor por trealose devem ser testados, visto que este último produziu bons resultados e não apresentou efeitos tóxicos nos estudos já publicados.

enhances renal excretion of advanced glycation endproducts in vivo and suppresses adverse AGEmediated cellular effects in vitro: a potential AGE sequestration theraphy for diabetic nephropathy? Mol Med. 2001;7:737-47.

12. Kern S, Eichler H, Stoeve J, Kluter H, Bieback K. Comparative analysis of mesenchymal stem cells from bone marrow, umbilical cord blood, or adipose tissue. Stem Cells. 2006;24(5):1294-301.

13. Silva Jr. WA, Covas DT, Panepucci RA, ProtoSiqueira R, Siufi JLC, Zanette DL, Santos ARD, Zago MA. The profile of gene expression of human marrow mesenchymal stem cells. Stem Cells. 2003;21:661-9.

14. Molinaro E, Caputo LFG, Amendoeira MRR, organizadores. Conceitos e métodos para formação de profissionais em laboratórios de saúde, v. 2. Rio de Janeiro: Escola Politécnica de Saúde Joaquim Venâncio/Fundação Oswaldo Cruz; 2010. p.215-7.

15. Charbord P. Bone marrow mesenchymal stem cells: historical overview and concepts. Hum Gene Ther. 2010;21:1045-56.

16. Pountos I, Giannoudis PV. Biology of mesenchymal stem cells. Injury. 2005;36(Suppl 3):S8-S12.

17. Fadel L, Viana BR, Feitosa ML, Ercolin AC, Roballo KC, Casals JB, Pieri NC, Meirelles FV, Martins Ddos $\mathrm{S}$, Miglino MA, Ambrósio CE. Protocols for obtainment and isolation of two mesenchymal stem cell sources in sheep. Acta Cir Bras. 2011;26:267-73.

18. Harper E. Collagenases. Annu Rev Biochem. 1980;49:1063-78.

19. Wilson A, Butler PE, Seifalian AM. Adipose-derived stem cells for clinical applications: a review. Cell Prolif. 2011;44:86-98.

20. De Rosa A, De Francesco F, Tirino V, Ferraro GA, Desiderio V, Paino F, Pirozzi G, D'Andrea F, Papaccio G. A new method for cryopreserving adipose-derived stem cells: an attractive and suitable large-scale and long-term cell banking technology. Tissue Eng Part C Methods. 2009;15:659-67. 
Ladeira PRS et al. Cultivo de células-tronco derivadas de tecido adiposo:.

21. Rodrigues JP, Paraguassú-Braga FH, Carvalho L, Abdelhay E, Bouzas LF, Porto LC. Evaluation of trehalose and sucrose as cryoprotectants for hematopoietic stem cells of umbilical cord blood. Cryobiology. 2008;56:144-51.

22. Hino A, Mihara K, Nakashima K, Takano H. Trehalose levels and survival ratio of freeze-tolerant versus freeze-sensitive yeasts. Appl Environ Microbiol. 1990;56:1386-91.

23. Thirumala S, Gimble JM, Devireddy RV. Evaluation of methylcellulose and dimethyl sulfoxide as the cryoprotectants in a serum-free freezing media for cryopreservation of adipose-derived adult stem cells. Stem Cells Dev. 2010;19:513-22. 